\title{
Testing of drugs used for pre-sowing seed treatment
}

Grekhova I.V., Gilmanova M.V., Bazhutina L.A. GAU of Northern Trans-Urals, Tyumen, E-mail: grehova-rostok@mail.ru

Keywords: pre-sowing seed treatment, humic preparations, seedling method.

doi: 10.36291/HIT.2019.grekhova.062

To obtain high crop yields, the intensity of the initial processes of plant growth is of great importance. Scientific studies have established that pesticides can have a depressing effect on the physiological processes of cultivated plants. Some protectants have a negative effect on the linear growth of seedlings and germination. The effectiveness of pre-sowing treatment of seeds can be increased by the introduction of regulators or fertilizers into the solution of the protectants.

Research objective: evaluation of preparations for pre-sowing seed treatment by the method of seedlings.

The method of seedlings is based on the reaction of the test culture and allows you to determine the effect of drugs on the growth and development of plants. The following drugs were studied: Rostok - a humic preparation from peat (manufacturer of LLC «SPC "Evrika", Russia), Gumisol - a humic preparation from vermicompost (manufacturer of LLC «Agrofirm «Hermes», Ukraine), PreCede ${ }^{T M}$ - an aqueous mixture of nutrients (manufacturer ATR Nutrition, Canada). The seeds of the test culture (spring wheat) were soaked in water and preparations in a concentration according to the recommendations of the manufacturers. In glasses $(500 \mathrm{ml})$ filled with dark gray forest soil, 15 pieces were sown per vessel. The vessels were placed in an air conditioner at $t=20^{\circ} \mathrm{C}$ with a changeable program of day and night. Four repetitions. In the course of the experiment, the germination energy (on day 4), germination (on day 7 ), the length and mass of the root system and the terrestrial part of plants (on day 14) were recorded.

The seed germination energy in the control was 32\%, the tested drugs increased it: Rostok - 2.1 times, PreCede ${ }^{T M}-1.8$ times, Gumisol - 1.6 times. Germination was significantly increased by Rostok and PreCede ${ }^{\mathrm{TM}}$ preparations by 17 and $15 \%$, respectively. The drug Humisol reduced germination by $3 \%$; the difference with the control is not significant.

The development of the root system was positively affected by all the drugs studied, but to a different extent. The number of roots was most formed during seed treatment with Rostok, an increase of $18 \%$ to the control. PreCede ${ }^{\mathrm{TM}}$ and Gumisol increased the number of roots by 9 and 3\%, respectively, but the increase in the use of the last drug is not significant. According to the length of the root system, the difference between the preparations is not significant, an increase relative to the control: Rostok - $27 \%$, PreCede ${ }^{\mathrm{TM}}-27 \%$, Gumisol $-24 \%$. The mass of the root system exceeded the control: PreCede $^{\mathrm{TM}}$ - by $55 \%$, Rostok - by $53 \%$, Gumisol - by $19 \%$. The difference between the first two drugs in this indicator is not significant; the last drug is significantly inferior to the previous ones.

According to the length and weight of the plants, the greatest increase in control was obtained from the use of the Rostok preparation -38 and $93 \%$, respectively. PreCede ${ }^{\mathrm{TM}}$ had an average effect on these parameters, an increase of 17 and 24\%. The lowest increases from the drug Gumisol -10 and $2 \%$, respectively, the increase in plant mass is not significant.

Thus, we recommend adding the Rostok humic preparation to the protectant mixture. 